\title{
Perfil del sector de alta tecnología en México: Una aproximación a la realidad
}

\section{Profile of the high technology sector in Mexico: An approximation to reality}

\author{
VILLALOBOS-ALONZO, María de los Ángeles†** \& ROMO-GONZÁLEZ, Ana Eugenia
}

Universidad Tecnológica de Jalisco, México.

ID $1^{\mathrm{er}}$ Autor: María de los Ángeles, Villalobos-Alonzo / ORC ID: 0000-0003-3052-8271, CVU CONACYT ID: 12718

ID 1r Coautor: Ana Eugenia, Romo-González / ORC ID: 0000-0002-4653-2593, CVU CONACYT ID: 212291

DOI: $10.35429 /$ JTO.2020.14.4.6.21

Recibido 15 de Julio, 2020, Aceptado, 30 de Diciembre, 2020

\begin{abstract}
Resumen
El presente artículo es el resultado de una investigación exploratoria con el propósito de elucidar el perfil de las empresas de Alta tecnología (AT) en México, con relación a los procesos de investigación y desarrollo tecnológico, inversión y de cooperación. La información fue obtenida a través de un cuestionario digital que se les hizo llegar a las empresas por vía internet. Participaron 112 compañías de los sectores de Aeroespacial, Automotriz, Manufactura y TI de siete entidades federativas que cuentan con al menos cinco sectores especializados en Alta Tecnología; Baja California, Chihuahua, el Estado de México, Jalisco, Nuevo León, Puebla y Querétaro. Para el procesamiento de los datos se utilizaron técnicas de estadística descriptiva. De las realidades posiblemente conocidas es que las empresas nacionales se sitúan en AT por el giro o actividad de la empresa, y no por obtener resultados como parte de un intenso proceso de Investigación y Desarrollo Tecnológico (IDT). Estos hallazgos son una ruta para la reflexión y diseño de estrategias que vinculen a diversos actores para dar soluciones de forma conjunta la industria, sociedad, la academia y gobierno contribuyen a posicionar a México en el marco internacional de la economía del conocimiento y el logro de mejores resultados económicos empresariales a partir de las consecuencias obtenidas de actividades de innovación.
\end{abstract}

Estudio exploratorio, Procesos de investigación y desarrollo tecnológico, Inversión y cooperaciónl

\begin{abstract}
This article is the result of an exploratory research with the purpose of elucidating the profile of High Technology (TA) companies in Mexico, in relation to the processes of technological research and development, investment and cooperation. The information was obtained through a digital questionnaire that was sent to the companies via the internet. 112 companies from the Aerospace, Automotive, Manufacturing and IT sectors from seven states that have at least five sectors specialized in High Technology participated; Baja California, Chihuahua, the State of Mexico, Jalisco, Nuevo León, Puebla and Querétaro. Descriptive statistics techniques were used to process the data. One of the possibly known realities is that national companies are located in TA because of the company's line of work or activity, and not because of obtaining results as part of an intense Technological Research and Development process (TRD). These findings are a route for reflection and design of strategies that link various actors to jointly provide solutions: industry, society, academia, and government contribute to position México in the international framework of the knowledge economy and the achievement of better business economic results from the consequences obtained from innovation activities.
\end{abstract}

Exploratory study, Research and technological development processes, Investment and cooperation

Citación: VILLALOBOS-ALONZO, María de los Ángeles \& ROMO-GONZÁLEZ, Ana Eugenia. Perfil del sector de alta tecnología en México: Una aproximación a la realidad. Revista de Operaciones Tecnológicas. 2020. 4-14:6-21.

$\dagger$ Investigador contribuyendo como primer autor. 


\section{Introducción}

El desarrollo económico de México ya no puede seguir dependiendo de su localización geográfica con los mercados, de la explotación de sus recursos naturales o de la preparación de mano de obra barata para crecer (Corral y Ramos, 2012). Es evidente, que el mayor reto se encuentra en el desarrollo de capacidades de innovación en las organizaciones, en donde su resultado sea la creación de innovación en múltiples sectores de aplicación, como el de Alta Tecnología.

\section{Alta tecnología y su aproximación conceptual}

De acuerdo con Oakey, Rothwell y Cooper, (1988); Viardot, (2004); Mohr, Sengupta y Slater (2009), no existe un concepto único, universalmente aceptado que describa lo que debe entenderse por empresa de Alta tecnología con exactitud, esto se debe a su naturaleza cambiante y al dinamismo del entorno en que se desenvuelven (McKenna, 1985; Moriarty y Kosnik, 1989).

Con el fin de una aproximación a la construcción del concepto de empresas de alta tecnología, es necesario entender ¿qué es la tecnología? La Real Academia de la Lengua Española (2014) la define como el conjunto de teorías y técnicas que permiten el aprovechamiento práctico del conocimiento científico, y el conjunto de los instrumentos y procedimientos industriales de un determinado sector o producto. Gutiérrez (2004) y Burgelman, Christensen y Wheelwright, (2009) mencionan que es el conocimiento práctico, teórico, habilidades y artefactos que pueden ser usados en desarrollar productos y servicios.

Mediante la tecnología, las empresas son capaces de usar sistemáticamente los conocimientos para producir materiales útiles, componentes, sistemas, o métodos, incluyendo el desarrollo de prototipos, procesos, productos y servicios (González, 1998). Así, la tecnología es un proceso que abarca las ideas implicadas en la fabricación de un producto (Mohr, et. al., 2009).
En este contexto, la aproximación al concepto de empresas de alta tecnología se entenderá como: las entidades que tratan de desarrollar y explotar comercialmente una innovación tecnológica que implica una elevada incertidumbre (Storey y Tether, 1998), que se evalúan mediante un esquema establecido por organismos internacionales, que representa una medida de los resultados y del impacto de la investigación y desarrollo (I+D) y constituyen una herramienta de gran utilidad para el análisis de la competitividad e internacionalización de la economía (INE, 2002) de los países.

\section{México y la clasificación de los sectores de Alta Tecnología internacionales}

Las actividades de innovación en el sector empresarial son un factor clave para el logro de mayor productividad y competitividad de las organizaciones y en general, para el crecimiento de una economía (Méndez, 2002). De las diversas actividades que alcanza la innovación, las de investigación y desarrollo Tecnológico (I+D) juegan un papel muy importante en el desarrollo de países, regiones y localidades (Báscolo, Castagna y Woelflin, 2012), al convertirse en una fuente de valor agregado y de riqueza para ese territorio (Ruíz, 2004).

Para determinar el nivel de innovación, productividad y competitividad de los sectores industriales, existen diversas clasificaciones, entre los que destacan la de intensidad tecnológica de la OCDE (Hatzichronoglu, 1997), la Clasificación Industrial Internacional Uniforme de todas las actividades económicas CIIU (ISIC Rev.4) de las Naciones Unidas (2009), la Clasificación Nacional de Actividades Económicas (CNAE, 2009) en España y el Sistema de Clasificación Industrial de América del Norte, México (SCIAN, 2013).

En relación a la intensidad tecnológica, la OCDE realizó la primera propuesta de clasificación de los sectores de alta tecnología, que comprende el análisis de la industria en el periodo de 1970-1980 (Molero- Zayas e Hidalgo, 2003), la cual los agrupó de acuerdo con su intensidad tecnológica en tres indicadores relacionados con $\mathrm{I}+\mathrm{D} ; 1$ ) el gasto con el valor añadido, 2) producción y 3) con los tipos de tecnología que se incorporan tanto en los bienes intermedios como en los de inversión para la producción (Tabla 1). 
Sectores de alta intensidad en I+D según la OCDE

\begin{tabular}{|c|c|c|}
\hline $\begin{array}{l}\text { Clasificación } \\
\text { Tecnológica }\end{array}$ & $\begin{array}{l}\text { Dígitos } \\
\text { ISIC Rev. } \\
3\end{array}$ & Literal ISIC \\
\hline \multirow[t]{5}{*}{ Alta tecnología } & 353 & $\begin{array}{l}\text { Fabricación de aeronaves } \\
\text { y naves espaciales }\end{array}$ \\
\hline & 30 & $\begin{array}{lr}\text { Fabricación } & \text { de } \\
\text { maquinaria de } & \text { oficina, } \\
\text { contabilidad } & \mathrm{e} \\
\text { informática } & \\
\end{array}$ \\
\hline & 32 & 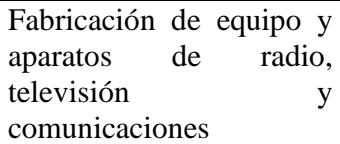 \\
\hline & 2423 & Industria farmacéutica \\
\hline & 33 & $\begin{array}{l}\text { Fabricación de } \\
\text { instrumentos médicos, } \\
\text { ópticos y de precisión }\end{array}$ \\
\hline \multirow[t]{5}{*}{$\begin{array}{l}\text { Media-alta } \\
\text { tecnología }\end{array}$} & 34 & $\begin{array}{l}\text { Fabricación de vehículos } \\
\text { automotores, remolques y } \\
\text { semirremolques }\end{array}$ \\
\hline & $\begin{array}{r}24 \text { excl.- } \\
2423 \\
\end{array}$ & $\begin{array}{l}\text { Fabricación de sustancias } \\
\text { y productos químicos }\end{array}$ \\
\hline & 29 & $\begin{array}{l}\text { Fabricación } \\
\text { maquinaria } \\
\text { mecánico }\end{array}$ \\
\hline & 31 & $\begin{array}{l}\text { Fabricación } \\
\text { maquinaria } \\
\text { eléctricos }\end{array}$ \\
\hline & $352+359$ & $\begin{array}{l}\text { Fabricación de material } \\
\text { ferroviario y otro } \\
\text { material de transporte }\end{array}$ \\
\hline \multirow[t]{5}{*}{$\begin{array}{l}\text { Media-baja } \\
\text { tecnología }\end{array}$} & 34 & $\begin{array}{l}\text { Fabricación de vehículos } \\
\text { automotores, remolques y } \\
\text { semirremolques }\end{array}$ \\
\hline & $\begin{array}{r}24 \text { excl.- } \\
2423 \\
\end{array}$ & $\begin{array}{l}\text { Fabricación de sustancias } \\
\text { y productos químicos }\end{array}$ \\
\hline & 29 & $\begin{array}{l}\text { Fabricación } \\
\text { maquinaria } \\
\text { mecánico }\end{array}$ \\
\hline & 31 & $\begin{array}{lr}\begin{array}{l}\text { Fabricación } \\
\text { maquinaria } \\
\text { eléctricos }\end{array} & \text { y aparatos } \\
\end{array}$ \\
\hline & $352+359$ & $\begin{array}{l}\text { Fabricación de material } \\
\text { ferroviario y otro } \\
\text { material de transporte }\end{array}$ \\
\hline \multirow[t]{4}{*}{ Baja tecnología } & $20+22$ & $\begin{array}{l}\text { De Reproducción de } \\
\text { grabaciones }\end{array}$ \\
\hline & $36-37$ & $\begin{array}{l}\text { Producción de madera y } \\
\text { fabricación de productos } \\
\text { de madera y corcho, } \\
\text { excepto } \\
\text { Fabricación de artículos } \\
\text { de paja y materiales } \\
\text { trenzables. }\end{array}$ \\
\hline & $15-16$ & $\begin{array}{l}\text { Elaboración de productos } \\
\text { alimenticios, bebidas y } \\
\text { de productos de tabaco }\end{array}$ \\
\hline & $17+19$ & $\begin{array}{l}\text { Fabricación de productos } \\
\text { textiles, curtido y adobo } \\
\text { de cuero, fabricación de } \\
\text { maletas, Bolsos de mano, } \\
\text { artículos de talabartería y } \\
\text { guarnicionería y calzado }\end{array}$ \\
\hline
\end{tabular}

Tabla 1 Sectores de Alta intensidad Fuente: INE (2002); OCDE (2011b)
La Organización Mundial de las Naciones Unidas (2009) describe la Clasificación Industrial Internacional Uniforme de todas las actividades económicas (CIIU) (ISIC Rev.4) como una estructura de clasificación coherente y consistente de las actividades económicas basada en un conjunto de conceptos, definiciones, principios y normas de clasificación. La cual, proporciona un marco general en que los datos económicos pueden reunirse y divulgarse en un formato diseñado para fines de análisis económico, adopción de decisiones y elaboración de políticas (Tabla 2).

\begin{tabular}{|c|c|c|c|}
\hline \multicolumn{4}{|c|}{$\begin{array}{l}\text { Clasificación ISIC Rev. } 4 \\
\text { C 10-33 Industrias manufactureras }\end{array}$} \\
\hline División & Grupo & Clase & Descripción de la Clase \\
\hline \multirow[t]{4}{*}{26} & 262 & 2620 & $\begin{array}{l}\text { Fabricación de ordenadores y } \\
\text { equipo periférico }\end{array}$ \\
\hline & 263 & 2630 & $\begin{array}{l}\text { Fabricación de equipo de } \\
\text { comunicaciones }\end{array}$ \\
\hline & 266 & 2660 & $\begin{array}{l}\text { Fabricación de equipo de } \\
\text { irradiación y } \\
\text { electrónico de uso médico y } \\
\text { terapéutico }\end{array}$ \\
\hline & 268 & 2680 & $\begin{array}{l}\text { Fabricación de soportes } \\
\text { magnéticos y ópticos. }\end{array}$ \\
\hline \multirow[t]{4}{*}{27} & 273 & 2731 & $\begin{array}{l}\text { Fabricación de cables y } \\
\text { dispositivos de cableado } \\
\text { Fabricación de cables de } \\
\text { fibra óptica }\end{array}$ \\
\hline & & 2732 & $\begin{array}{l}\text { Fabricación de otros hilos y } \\
\text { cables eléctricos }\end{array}$ \\
\hline & & 2733 & $\begin{array}{l}\text { Fabricación de dispositivos } \\
\text { de cableado }\end{array}$ \\
\hline & 275 & 2750 & $\begin{array}{l}\text { Fabricación de aparatos de } \\
\text { uso doméstico }\end{array}$ \\
\hline \multirow[t]{3}{*}{29} & 291 & 2910 & $\begin{array}{l}\text { Fabricación de vehículos } \\
\text { automotores }\end{array}$ \\
\hline & 292 & 2920 & $\begin{array}{l}\text { Fabricación de carrocerías } \\
\text { para vehículos automotores; } \\
\text { fabricación de remolques y } \\
\text { semirremolques. }\end{array}$ \\
\hline & 293 & 2930 & $\begin{array}{l}\text { Fabricación de partes, piezas } \\
\text { y accesorios para vehículos } \\
\text { automotores. }\end{array}$ \\
\hline \multirow[t]{3}{*}{30} & 302 & 3020 & $\begin{array}{l}\text { Fabricación de locomotoras y } \\
\text { material rodante }\end{array}$ \\
\hline & 303 & 3030 & $\begin{array}{l}\text { Fabricación de aeronaves, } \\
\text { naves espaciales y } \\
\text { maquinaria conexa }\end{array}$ \\
\hline & 304 & 3040 & $\begin{array}{l}\text { Fabricación de vehículos } \\
\text { militares de combate }\end{array}$ \\
\hline División & Grupo & Clase & Descripción de la Clase \\
\hline \multirow[t]{3}{*}{62} & & 6201 & Programación informática \\
\hline & & 6202 & $\begin{array}{l}\text { Consultoría de informática y } \\
\text { gestión de instalaciones } \\
\text { informáticas }\end{array}$ \\
\hline & & 6209 & $\begin{array}{l}\text { Otras actividades de } \\
\text { tecnología de la información } \\
\text { y de servicios informáticos }\end{array}$ \\
\hline 63 & 639 & 6399 & $\begin{array}{llr}\text { Otras } & \text { actividades de } \\
\text { servicios } & \text { de información } \\
\text { n.c.p. } & & \\
\end{array}$ \\
\hline
\end{tabular}

Tabla 2 Clasificación Industrial Internacional Uniforme de todas las actividades económicas (CIIU) (ISIC Rev.4) Fuente: ONU, (2009)

VILLALOBOS-ALONZO, María de los Ángeles \& ROMO-GONZÁLEZ, Ana Eugenia. Perfil del sector de alta tecnología en México: Una aproximación a la realidad. Revista de Operaciones Tecnológicas. 2020 
El ISIC Rev. 4 se encuentra estructurado de manera descendente con una orden jerárquico que comprende 21 Secciones (alfabetizadas), división, grupo, clase y descripción, de los cuáles se retoman los sectores de alta tecnología de la sección C Industrias manufactureras, las divisiones 26 Fabricación de productos de informática, de electrónica y de óptica, 27 Fabricación de equipo eléctrico, 29 Fabricación de vehículos automotores, remolques y semirremolques y 30 Fabricación de otro equipo de transporte. La sección J Información y Comunicación las divisiones 62 Programación informática, consultoría de informática y actividades conexas y 63 Actividades de servicios de información.

Por último, el Sistema de Clasificación Industrial de América del Norte, México (SCIAN, 2013), Clasificación Industrial Internacional Uniforme Rev. 4, CIIU Rev. 4, la cual es una categorización económica que permite la agrupación de datos de manera sistematizada y homogénea para facilitar el análisis e interpretación de la actividad económica, así como refleja con precisión la estructura económica dividida en 20 sectores de un país (INEGI, 2015).

\begin{tabular}{|c|c|}
\hline \multicolumn{2}{|c|}{$\begin{array}{c}\text { SCIAN México 2013-Clasificación Industrial Internacional } \\
\text { Uniforme Rev. 4, CIIU Rev. } 4\end{array}$} \\
\hline División & Sectores \\
\hline 11 & $\begin{array}{l}\text { Agricultura, cría y explotación de animales, } \\
\text { aprovechamiento forestal, pesca y caza }\end{array}$ \\
\hline 21 & Minería \\
\hline 22 & $\begin{array}{l}\text { Generación, transmisión y distribución de energía } \\
\text { eléctrica, suministro de agua y de gas por ductos al } \\
\text { consumidor final }\end{array}$ \\
\hline 23 & Construcción \\
\hline $31-33$ & Industrias manufactureras \\
\hline 43 & Comercio al por mayor \\
\hline 46 & Comercio al por menor \\
\hline $48-49$ & Transportes, correos y almacenamiento \\
\hline 51 & Información en medios masivos \\
\hline 52 & Servicios financieros y de seguros \\
\hline 53 & $\begin{array}{l}\text { Servicios inmobiliarios y de alquiler de bienes } \\
\text { muebles e intangibles }\end{array}$ \\
\hline 54 & Servicios profesionales, científicos y técnicos \\
\hline 55 & Corporativos gubernamentales \\
\hline 56 & $\begin{array}{l}\text { Servicios de apoyo a los negocios y manejo de } \\
\text { residuos y desechos, y servicios de remediación }\end{array}$ \\
\hline 61 & Servicios educativos \\
\hline 62 & Servicios de salud y de asistencia social \\
\hline 71 & $\begin{array}{l}\text { Servicios de esparcimiento culturales y deportivos, } \\
\text { y otros servicios recreativos }\end{array}$ \\
\hline 72 & $\begin{array}{l}\text { Servicios de alojamiento temporal y de preparación } \\
\text { de alimentos y bebidas }\end{array}$ \\
\hline 81 & $\begin{array}{l}\text { Otros servicios } \\
\text { gubernamentales }\end{array}$ \\
\hline 93 & $\begin{array}{l}\text { Actividades legislativas, gubernamentales, de } \\
\text { impartición de justicia y de organismos } \\
\text { internacionales y extraterritoriales }\end{array}$ \\
\hline
\end{tabular}

Tabla 3 Clasificación de los sectores industriales en México SCIAN (INEGI, 2013)

ISSN: 2523-6806

ECORFAN ${ }^{\circledR}$ Todos los derechos reservados
Del SCIAN (2013) se retoman tres sectores 31-33 Industrias manufactureras, 51 Información en medios masivos y 54 servicios profesionales, científicos y tecnológicos para fines de este estudio (Tabla 3 ).

\section{Los 4 sectores de alta tecnología en México}

México en los últimos 30 años, ha experimentado una profunda transformación en su estructura productiva, como resultado de un proceso de apertura e integración a la economía internacional, que ha puesto a prueba la capacidad del sector productivo para adaptarse a un entorno caracterizado por factores como la productividad, competitividad, competencia económica, innovación, cadenas globales de valor, contenido nacional, mejora regulatoria, bloques comerciales y facilitación comercial, que habían estado ausentes o limitados en torno a una transición institucional lenta, de un modelo de economía cerrada a uno de apertura al mercado global (DOF, 2018).

En este contexto, México estructuró una estrategia de apertura e integración de comercio internacional en 1986, consolidando una red de 12 Tratados de Libre Comercio (TLC's) que de acuerdo con DOF (2015) ofrecen a los bienes y servicios nacionales un acceso preferencial en 45 países que concentran más de mil 140 millones de consumidores potenciales, $59.7 \%$ del Producto Interno Bruto y 55\% del comercio a nivel mundial (Tabla 4).

\begin{tabular}{|c|c|}
\hline \multicolumn{2}{|c|}{$\begin{array}{l}\text { Histórico del producto interno bruto México } \\
\text { Datos del Banco Mundial }\end{array}$} \\
\hline \multirow[t]{2}{*}{ Año } & México \\
\hline & US $\$$ billones \\
\hline 1971 & 36.74 \\
\hline 1972 & 44.00 \\
\hline 1973 & 54.54 \\
\hline 1974 & 55.51 \\
\hline 1975 & 63.20 \\
\hline 1976 & 65.46 \\
\hline 1977 & 73.72 \\
\hline 1978 & 91.91 \\
\hline 1979 & 122.92 \\
\hline 1980 & 137.57 \\
\hline 1981 & 160.23 \\
\hline 1982 & 200.52 \\
\hline 1983 & 163.51 \\
\hline 1984 & 157.36 \\
\hline 1985 & 163.79 \\
\hline 1986 & 152.28 \\
\hline 1987 & 150.26 \\
\hline 1988 & 146.41 \\
\hline 1989 & 175.89 \\
\hline 1990 & 214.50 \\
\hline 1991 & 252.38 \\
\hline
\end{tabular}

VILLALOBOS-ALONZO, María de los Ángeles \& ROMO-GONZÁLEZ, Ana Eugenia. Perfil del sector de alta tecnología en México: Una aproximación a la realidad. Revista de Operaciones Tecnológicas. 2020 


\begin{tabular}{|r|r|}
\hline 1992 & 294.83 \\
\hline 1993 & 324.95 \\
\hline 1994 & 368.68 \\
\hline 1995 & 304.60 \\
\hline 1996 & 341.72 \\
\hline 1997 & 348.60 \\
\hline 1998 & 368.10 \\
\hline 1999 & 428.80 \\
\hline 2000 & 498.00 \\
\hline 2001 & 550.30 \\
\hline 2002 & 596.70 \\
\hline 2003 & 637.16 \\
\hline 2004 & 703.08 \\
\hline 2005 & 753.39 \\
\hline 2006 & 820.32 \\
\hline 2007 & 878.02 \\
\hline 2008 & $1,061.44$ \\
\hline 2009 & 962.70 \\
\hline 2010 & $1,012.32$ \\
\hline 2011 & $1,081.77$ \\
\hline 2012 & $1,176.87$ \\
\hline 2013 & $1,216.09$ \\
\hline 2014 & $1,237.53$ \\
\hline 2015 & $1,233.66$ \\
\hline 2016 & $1,076.91$ \\
\hline 2017 & $1,112.53$ \\
\hline 2018 & $1,157.97$ \\
\hline 2019 & $1,203.62$ \\
\hline 2020 & \\
\hline & 15 México \\
\hline & \\
\hline
\end{tabular}

Tabla 4 Evolución Histórica del PIB México Fuente: Datos del Banco Mundial (2020)

El manejo de un modelo económico abierto y flexible para México ha permitido obtener un alza en el PIB (aún no del todo satisfactoria), como se muestra en histórico de la Tabla 1. Es importante señalar tres caídas significativas en el PIB, en 1995 por la falta de reservas internacionales a causa de la devaluación del peso mexicano y 2001 y 2009 por la desaceleración económica que sufrió los Estados Unidos de Norteamérica.

De las industrias con mayor aportación al PIB en México, se encuentra la manufacturera, de acuerdo con Hausmann, Hidalgo, Bustos, Coscia, Chung, Jiménez, y Yıldırım, (2011), México se ubica en la posición 20 a nivel mundial en cuanto a la complejidad económica, de los bienes que exporta.

En 2010 se mantuvo en el noveno país exportador de manufactura de alta tecnología. El 50\% de las exportaciones para el 2012 fueron de manufactura en media y alta tecnología (DOF, 2013).
El Producto Interno Bruto al 2019 fue de 18,5 billones de pesos mexicanos, por sector económico e intensidad tecnológica (INEGI, 2015) se distribuyó de la siguiente manera Tabla 5:

\begin{tabular}{|c|c|c|c|}
\hline \multicolumn{4}{|c|}{ Porcentaje del PIB por sector económico } \\
\hline $\begin{array}{l}\text { Tipo de } \\
\text { Industria }\end{array}$ & $\begin{array}{l}\text { Participación en el } \\
\text { PIB } \\
\text { manufacturero }\end{array}$ & Industrias & $\begin{array}{l}\text { Fuentes de } \\
\text { Innovación }\end{array}$ \\
\hline $\begin{array}{l}\text { Baja } \\
\text { Tecnología }\end{array}$ & 43.3 & $\begin{array}{l}\text { Comestibles, } \\
\text { productos de } \\
\text { madera, } \\
\text { tabaco, } \\
\text { textiles y } \\
\text { prendas de } \\
\text { vestir entre } \\
\text { otros }\end{array}$ & $\begin{array}{l}\text { Proveedores } \\
\text { de la } \\
\text { siguiente } \\
\text { cadena } \\
\text { (maquinaria, } \\
\text { química, y } \\
\begin{array}{l}\text { de normas o } \\
\text { reglas de } \\
\text { calidad. }\end{array}\end{array}$ \\
\hline $\begin{array}{l}\text { Media-Baja } \\
\text { tecnología }\end{array}$ & 16.3 & $\begin{array}{lr}\text { Industria } & \\
\text { básica del } \\
\text { metal y } \\
\text { productos } \\
\text { metálicos, } \\
\text { muebles, } \\
\text { petróleo y } \\
\text { carbón y sus } \\
\text { derivados }\end{array}$ & $\begin{array}{l}\text { La } \\
\text { innovación se } \\
\text { centra en } \\
\text { procesos de } \\
\text { insumo- } \\
\text { producto, con } \\
\text { un } \\
\text { incremento en } \\
\text { la orientación } \\
\text { de diseño. } \\
\end{array}$ \\
\hline $\begin{array}{l}\text { Media-alta } \\
\text { tecnología }\end{array}$ & 29.6 & $\begin{array}{l}\text { Industria } \\
\text { automovilístic } \\
\text { a y de } \\
\text { transporte, } \\
\text { industria, } \\
\text { química, } \\
\text { maquinaria y } \\
\text { equipo }\end{array}$ & $\begin{array}{l}\text { Diseño, } \\
\text { proceso, } \\
\text { sistemas de } \\
\text { producción } \\
\text { complejos, } \\
\text { cadena de } \\
\text { valor, } \\
\text { investigación } \\
\text { y desarrollo a } \\
\text { nivel de la } \\
\text { empresa. }\end{array}$ \\
\hline $\begin{array}{l}\text { Alta } \\
\text { tecnología }\end{array}$ & 10.8 & $\begin{array}{l}\text { Industria } \\
\text { electrónica, } \\
\text { farmacéutica, } \\
\text { informática y } \\
\text { computación, } \\
\text { equipo de } \\
\text { precisión y } \\
\text { aeroespacial. }\end{array}$ & $\begin{array}{l}\text { Alto grado de } \\
\text { investigación } \\
\text { y desarrollo } \\
\text { en la } \\
\text { empresa, } \\
\text { vinculada con } \\
\text { centros de } \\
\text { investigación } \\
\text { y con } \\
\text { universidades }\end{array}$ \\
\hline
\end{tabular}

Tabla 5 Porcentaje del PIB por sector económico 2018 Fuente: Elaboración propia a partir de Ruíz (2008) e INEGI (2019)

Los sectores industriales de manufactura media-alta tecnología y Alta tecnología generaron el $40.4 \%$ de la participación del PIB en la economía mexicana. El sector de alta tecnología por si solo aportó el $10.8 \%$, ya que de acuerdo con la OCDE (2012) la inversión empresarial en I+D en México es reducida. Ruiz (2008) menciona que las empresas de alta tecnología requieren de un alto grado de investigación y desarrollo para generar bienes de alta valor para la nación. 
En México el gasto interno bruto en investigación y desarrollo (I+D) del país reportado en el 2012-2016 represento apenas el $0.44 \%$ del PIB, indicando el porcentaje más bajo de la OCDE.

México establece estrategias para fomentar la innovación para impulsar la productividad y crear nuevas fuentes de crecimiento como una prioridad enmarca en el Plan Nacional de Desarrollo 2013-2018 (PND, 2013) pretende mediante el Objetivo 3.5. "Hacer del desarrollo científico, tecnológico y la innovación pilares para el progreso económico y social sostenible. El PECiTI (2014-2018) se alinea con el PND estableciendo el objetivo 3.5.1. Contribuir a que la inversión nacional en investigación científica y desarrollo tecnológico crezcan anualmente y alcance un nivel de 1\% del PIB.", mientras que el Programa de Desarrollo Innovador 20132018 (PDI) de la Secretaría de Economía (SE, 2013) tiene como Objetivo sectorial 1. "Desarrollar una política de fomento industrial y de innovación que promueva un crecimiento económico equilibrado por sectores, regiones y empresas".

\section{Metodología para desarrollar}

La naturaleza del estudio es exploratoria ya que permite el acercamiento a fenómenos de estudio relativamente desconocidos y a su vez, sugieren afirmaciones (postulados) verificables (Danhke, 1976). Además, la interrelación con tres intenciones de acuerdo con Zikmund y Babin, (2009): el diagnostico de una situación, selección de alternativas y el descubrimiento de nuevas ideas.

La población está formada por la totalidad (conjunto) de las observaciones en las cuales se tiene interés (Pérez, 2012). El interés de esta investigación se centra en la unidad de análisis "empresas o unidades de negocio" (Adler, 1989), enfocadas a la Alta tecnología de México con respecto a la Clasificación ISIC Rev. 4, en los sectores 62 y 63 (Tecnologías de la Información y la Comunicación), 26 y 27 (Manufactura electrónica), 29 (Plantas para la fabricación de vehículos ligeros y pesados) y 28 (Aeroespacial).
Las razones para seleccionar las empresas de alta tecnología como unidad de análisis de este estudio radican en que: 1) son un motor económico para los países al generar bienes con alto valor (Barceló, 2001), 2) requieren un continuo esfuerzo en investigación y una sólida base tecnológica (Molero-Zayas e Hidalgo, 2003), 3) participan en contextos económicos altamente dinámicos y su principal activo es el conocimiento (Caravaca, González, García, Fernández y Mendoza, 2014) y 4) aportan a la economía de una nación a través del comercio de bienes de alta tecnología (BAT).

La tipificación de sectores se realiza con base en los análisis de González, (2012); Rodríguez-Pose, (2012), donde se identifica que existen 38 centros de alta tecnología relacionados, de acuerdo con el sector de TI, en 28 de las 32 entidades federativas, y 28 parques industriales en 19 entidades (Foro consultivo, científico y tecnológico A.C. [FCCyT], 2013), a su vez, las plantas del área automotriz están distribuidas en 19 entidades (SE, 2014) y, enfocadas al sector aeroespacial 197 empresas concentradas principalmente en estados fronterizos con Estados Unidos de América (PROMÉXICO, 2013).

Se identifica que entre los estados que cuentan con al menos cinco sectores especializados en Alta Tecnología son Baja California, Chihuahua, el Estado de México, Jalisco, Nuevo León, Puebla y Querétaro, mismos que según el Instituto Mexicano para la competitividad A.C. (IMCO, 2013) ocupan los primeros lugares del ranking de competitividad estatal, por lo que estas siete serán consideradas como parte de la muestra.

Las variables del estudio se describen en la siguiente Tabla 6: 


\begin{tabular}{|c|c|c|}
\hline \multicolumn{3}{|c|}{ Empresas de Alta Tecnología (EAT) } \\
\hline Dimensiones & $\begin{array}{l}\text { Definición } \\
\text { Conceptual }\end{array}$ & Indicadores \\
\hline $\begin{array}{lr}\text { Proceso } & \text { de } \\
\text { investigación } & \text { y } \\
\text { desarrollo (IDT) } & \end{array}$ & $\begin{array}{l}\text { Es el conjunto de } \\
\text { actividades } \\
\text { emprendidas de forma } \\
\text { sistemática, afín de } \\
\text { aumentar el caudal de } \\
\text { conocimientos } \\
\text { científicos y técnicos, } \\
\text { así como la utilización } \\
\text { de los resultados de } \\
\text { estos trabajos para } \\
\text { conseguir nuevos } \\
\text { dispositivos, materiales } \\
\text { productos, mastat, } \\
\text { o procesos. (Eusta } \\
\text { 2015a), a través del } \\
\text { capital humano en } \\
\text { IDT, como insumo } \\
\text { dedicado al proceso } \\
\text { innovador y los } \\
\text { productos yos } \\
\text { resultados obtenidos } \\
\text { de él (En Ramírez } \\
\text { 2013: Godin, 1996; } \\
\text { Crépon, Duguet y } \\
\text { Mairesse, 1998; } \\
\text { OCDE, 1997 y 2005; } \\
\text { Rogers, 1998; Lööf y } \\
\text { Heshmati, 2002; } \\
\text { Romo y Hill, 2006). }\end{array}$ & $\begin{array}{l}\text { Capital Humano } \\
\text { Producción } \\
\text { científica } \\
\text { tecnológica }\end{array}$ \\
\hline Inversión & $\begin{array}{l}\text { Son los gastos en } \\
\text { actividades de } \\
\text { investigación } \\
\text { científica y desarrollo } \\
\text { tecnológico realizados } \\
\text { dentro de la Unidad o } \\
\text { Centro investigador de } \\
\text { la empresa, cual quiera } \\
\text { que sea el origen de } \\
\text { los fondos, durante el } \\
\text { año de referencia. Los } \\
\text { gastos llevados a cabo } \\
\text { fuera del centro, pero } \\
\text { en apoyo de las tareas } \\
\text { de I+D internas } \\
\text { también se incluyen } \\
\text { (Eustat, 2015b). La } \\
\text { focalización de la } \\
\text { inversión en áreas, } \\
\text { proyectos o programas } \\
\text { son el resultado de la } \\
\text { planeación estratégica } \\
\text { (Chaves y Méndez, } \\
\text { 2015) de la } \\
\text { organización en I+D. }\end{array}$ & \begin{tabular}{l}
\multicolumn{2}{l}{ Gasto en I+D+I } \\
Fuentes \\
inversión \\
Áreas \\
inversión
\end{tabular} \\
\hline Cooperación & $\begin{array}{l}\text { La cooperación } \\
\text { empresarial o alianza } \\
\text { estratégica es el } \\
\text { conjunto de acuerdos o } \\
\text { contratos voluntarios } \\
\text { con un horizonte } \\
\text { temporal de medio y } \\
\text { largo plazo entre } \\
\text { empresas o sectores } \\
\text { independientes que } \\
\text { implican rer } \\
\text { intercambio } \\
\text { compartimiento de } \\
\text { recursos o capacidades } \\
\text { o incluso el desarrollo } \\
\text { de nuevos recursos } \\
\text { (Gulati, 1998). }\end{array}$ & $\begin{array}{lr}\text { Alianzas } & \text { y } \\
\text { sectores } & \text { de } \\
\text { cooperación. } & \end{array}$ \\
\hline
\end{tabular}

Tabla 6 Definición de variables del estudio
El diseño del instrumento ACIEAT (Villalobos, y González, 2015), se estructuro con 15 preguntas, tres dicotómicas, siete de abanico de respuestas, dos de. abanico de respuestas con un ítem abierta, tres numéricas y una porcentual como se muestra en la Tabla 7.

Variable Empresas de Alta tecnología (EAI)

Objetivo: El propósito de esta área es identificar los procesos de investigación y desarrollo tecnológico, inversión y de cooperación de las empresas de alta tecnología de México.

\begin{tabular}{|c|c|c|}
\hline Dimensiones & Indicadores & Ítems \\
\hline $\begin{array}{ll}\text { Datos } & \text { de } \\
\text { identificación } & \end{array}$ & $\begin{array}{l}\text { Giro de la } \\
\text { empresa }\end{array}$ & $\begin{array}{ll}\text { 1. Giro de empresa: } & \text { 1) } \\
\text { Local 2) Nacional } & \text { 3) } \\
\text { Internacional } & 4) \\
\text { Multinacional 5) Global 6) } \\
\text { Trasnacional }\end{array}$ \\
\hline \multicolumn{2}{|l|}{ Influencia geográfica } & 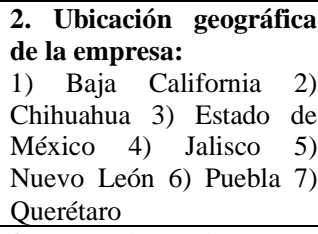 \\
\hline \multicolumn{2}{|l|}{ Sector industrial } &  \\
\hline \multicolumn{2}{|l|}{ Tamaño de la empresa } & $\begin{array}{l}\text { 4. Tamaño de la empresa 1) } \\
\text { Pequeña (menos de 20) } 2) \\
\text { Mediana (20-100) } \\
\text { Grande (mayor a 100) }\end{array}$ \\
\hline \multicolumn{2}{|c|}{ Agrupamiento empresarial } & $\begin{array}{l}\text { 5. iPertenece a un } \\
\text { conglomerado o clúster? } \\
\text { 1) Si 2) No }\end{array}$ \\
\hline \multicolumn{2}{|l|}{ Área de I+D+i } & $\begin{array}{l}\text { 6. Cuenta con área de } \\
\text { investigación, desarrollo } \\
\text { e innovación } \\
\text { 1) Si 2) No }\end{array}$ \\
\hline \multicolumn{2}{|c|}{$\begin{array}{l}\text { Localización geográfica del área de } \\
\text { investigación }\end{array}$} & $\begin{array}{l}\text { * Si la pregunta } 6 \text { es: } 6.1) \\
\text { ¿El área de I+D+i es? } \\
\text { Interna 2) Externa. } \\
\text { Ambas }\end{array}$ \\
\hline \multicolumn{2}{|l|}{ Registro RENIECYT } & $\begin{array}{l}\text { 7. Cuenta con Registro } \\
\text { Nacional de Instituciones y } \\
\text { Empresas Científicas y } \\
\text { Tecnológicas RENIECYT } \\
\text { 1) Si 2) No }\end{array}$ \\
\hline $\begin{array}{lr}\text { Proceso } & \text { de } \\
\text { investigación } & y \\
\text { desarrollo (IDT) } & \end{array}$ & $\begin{array}{l}\text { Capital } \\
\text { Humano }\end{array}$ & $\begin{array}{l}\text { 8. Indique el número de } \\
\text { personas que trabajan en la } \\
\text { empresa en actividades de } \\
\text { investigación y desarrollo } \\
\text { tecnológico (IDT): } \\
\text { 1) No. Doctorado 2) } \\
\text { 1) No. Maestría 3) } \\
\text { No. _- Especialidad 4) } \\
\text { No. Licenciatura 5) } \\
\text { Técnico }\end{array}$ \\
\hline \multicolumn{2}{|c|}{ Producción científica y tecnológica } & $\begin{array}{l}\text { 9. Cantidad de patentes } \\
\text { registradas por la } \\
\text { empresa en los últimos } 3 \\
\text { años } \\
\text { 10. Cantidad de modelos } \\
\text { de utilidad registrados por } \\
\text { la empresa en los últimos } 3 \\
\text { años } \\
\text { 11. Cantidad registros de } \\
\text { propiedad intelectual por la } \\
\text { empresa en los últimos } 3 \\
\text { años }\end{array}$ \\
\hline Inversión & $\begin{array}{l}\text { Gasto } \\
\mathrm{I}+\mathrm{D}+\mathrm{I}\end{array}$ & $\begin{array}{l}\text { 12. Registre el porcentaje } \\
\text { de gasto total dedicado a } \\
\text { investigación y desarrollo } \\
\text { tecnológico en su empresa } \\
\text { en los } 3 \text { últimos años }\end{array}$ \\
\hline
\end{tabular}

VILLALOBOS-ALONZO, María de los Ángeles \& ROMO-GONZÁLEZ, Ana Eugenia. Perfil del sector de alta tecnología en México: Una aproximación a la realidad. Revista de Operaciones Tecnológicas. 2020 


\begin{tabular}{|c|c|c|}
\hline Fuentes de inversión & &  \\
\hline Áreas de inversión & & $\begin{array}{l}\text { 14. El gasto en } \\
\text { investigación y desarrollo } \\
\text { tecnológico lo dedica a: a) } \\
\text { Formación de Capital } \\
\text { Humano b) Actualización } \\
\text { de Maquinaria c) } \\
\text { Infraestructura tecnológica } \\
\text { d) Procesos } \\
\text { Organizacionales } \\
\text { Vigilancia tecnológica. }\end{array}$ \\
\hline Cooperación & $\begin{array}{l}\text { Alianzas y } \\
\text { sectores de } \\
\text { cooperación }\end{array}$ & $\begin{array}{l}\text { 15. Mantiene alianzas de } \\
\text { cooperación 1) Si 2) No } \\
\text { 15.1 Indique el tipo de } \\
\text { alianza para realizar } \\
\text { investigación y desarrollo } \\
\text { tecnológico que mantiene: } \\
\text { a) Sector Productivo } \\
\text { (Subsidiarias, Empresas de } \\
\text { Alto riesgo, Empresas } \\
\text { privadas, Compañías } \\
\text { afiliadas o asociadas, } \\
\text { Instituciones de } \\
\text { Cooperación IDED) 15.1b } \\
\text { Indique el tipo de alianza } \\
\text { para realizar investigación } \\
\text { y desarrollo tecnológico } \\
\text { que mantiene b) Gobierno } \\
\text { (Federal, Estatal, } \\
\text { Municipal) 15.1c Indique } \\
\text { el tipo de alianza para } \\
\text { realizar investigación y } \\
\text { desarrollo tecnológico que } \\
\text { mantiene) Otras } \\
\text { Instituciones (Instituciones } \\
\text { de educación superior, } \\
\text { Instituciones privadas no } \\
\text { lucrativas, Organizaciones } \\
\text { internacionales). }\end{array}$ \\
\hline
\end{tabular}

Tabla 7 Construcción de ítems cuestionario

El instrumento obtuvo una fiabilidad de Alpha de Cronbach 0.825, en cuanto al criterio de validez de contenido, criterio y constructo.

En contenido se realizó la evaluación de jueces, La validez de contenido del instrumento se estimó mediante la cuantificación de los índices de concordancia y relevancia entre las evaluaciones de los jueces (Kerlinger y Lee, 2002) los cuales se calcularon mediante el coeficiente de Kappa de Fleiss (Fleiss, 1971) y la interpretación de los valores de la fuerza de concordancia mediante la clasificación propuesta por Landis y Koch (1977). Obteniendo un global de Fleiss de 0.861.
La validez de criterios se establece al validar un instrumento de medición al compararlo con algún criterio externo que pretende medir los mismo (Hernández, Fernández y Baptista., 2010). El grado de concomitancia (correlación) entre pruebas que apuntan a variables o constructos similares los denomina validez concurrente $\mathrm{o}$ validez criterio.

Los ítems desarrollados en el instrumento para indagar sobre la variable Empresa de alta tecnología se comparó con la encuesta de ESIDET de CONACYT-INEGI (2012) indicadores de las empresas en investigación y desarrollo tecnológico, obteniendo una correlación de Pearson 0.712 (correlación positiva alta) y desviación estándar del instrumento 1.960 y de la encuesta ESIDET de 1.208 .

En la validez de constructo se debe explicar el modelo teórico empírico que subyace a la variable de interés, mediante un constructo que es un atributo para explicar un fenómeno (Hernández, et al., 2010).

Para la validez de constructo y sus dimensiones se lleva a cabo un análisis factorial que es un modelo de regresión (Tello, Moscoso, Abad, Sanduvete-Chaves y García, 2015) que muestra las interrelaciones observadas entre un conjunto de variables y la relación entre la conceptualización teórica del instrumento y su estructura factorial.

En el análisis de la variable empresa se observa que las cargas factoriales son superiores a $<0.7$ se encuentran en el rango de satisfactorias y KMO .712.

Recolección de los datos del estudio descriptivo se llevó a cabo en el periodo de julio y agosto del 2015, mediante la aplicación del cuestionario ACIEAT, que fue contestado por diversos medios como: en la plataforma web, vía correo y telefónica por la dimensión del estudio, la estructura de recogida de datos se muestra en la Tabla 8. 


\section{Ficha técnica del estudio}

\begin{tabular}{|c|c|}
\hline $\begin{array}{l}\text { Población de la } \\
\text { investigación }\end{array}$ & $\begin{array}{l}297 \text { empresas de alta } \\
\text { tecnología de México }\end{array}$ \\
\hline Ámbito geográfico & $\begin{array}{l}7 \text { entidades federativas: } \\
\text { Baja California, } \\
\text { Chihuahua, Estado de } \\
\text { México, Jalisco, Nuevo } \\
\text { León, Puebla y } \\
\text { Querétaro. }\end{array}$ \\
\hline Sectores de Actividad & $\begin{array}{l}\text { Aeroespacial, } \\
\text { Automotriz, } \\
\text { Manufactura y TI. }\end{array}$ \\
\hline $\begin{array}{l}\text { Método de obtención de } \\
\text { la información }\end{array}$ & $\begin{array}{l}\text { Cuestionario en medios } \\
\text { digitales. }\end{array}$ \\
\hline $\begin{array}{ll}\text { Procedimiento } & \text { de } \\
\text { recolección de datos }\end{array}$ & $\begin{array}{l}\text { El cuestionario fue } \\
\text { enviado a toda la } \\
\text { muestra. }\end{array}$ \\
\hline $\begin{array}{l}\text { Número de cuestionarios } \\
\text { enviados }\end{array}$ & 297 \\
\hline Tasa de respuesta & $38 \%$ \\
\hline Tamaño de la muestra & 112 \\
\hline $\begin{array}{l}\text { Error de muestreo para } \\
\text { poblaciones finitas }\end{array}$ & $5.0 \%$ \\
\hline Nivel de Confianza & $95 \%$ \\
\hline $\begin{array}{l}\text { A quién se dirigió el } \\
\text { cuestionario }\end{array}$ & $\begin{array}{l}\text { Director o } \quad \text { gerente } \\
\text { general, director o } \\
\text { responsable del área de } \\
\text { I+D+i. }\end{array}$ \\
\hline Periodo de trabajo & Julio-agosto 2017 \\
\hline
\end{tabular}

Tabla 8 Ficha técnica del estudio

Manfreta, Bosnjak, Berzelak, Haas, y Vehovar, (2008) señalan que la tasa de respuesta de una encuesta de internet es inferior cuando se obtiene sólo el 11\% de participación del total de la muestra, el presente estudio obtuvo una tasa de respuesta del $38 \%$ que se acerca a una escala moderada, sugerida por Baxter y Babbie (2004) que señalan como regla de oro que una tasa de respuesta en cuestionarios por internet del $40 \%$ es moderada, $50 \%$ es adecuada, un $60 \%$ es buena, y un $70 \%$ es muy buena.

Se optó por realizar encuestas vía telefónica por dos motivos, en primer lugar, para aumentar la tasa de respuestas como menciona Dillman, Reips, y Matzat, (2009) "encontraron eficaz realizar una encuesta telefónica entre las personas que no habían contestado a una encuesta por internet" $y$ en segundo lugar para completar datos de cuestionarios con información incompleta.
La respuesta de la encuesta ACIEAT representa una cuarta parte de la muestra total del estudio, entre las razones que influyeron en la tasa de respuesta se encuentran; el difícil acceso a las empresas de alta tecnología, las políticas de confidencialidad de la empresa y por no contar con el área de $\mathrm{I}+\mathrm{D}+\mathrm{i}$ en la organización (descartando el llenado del cuestionario desde el primer momento, y encontrándose en esta situación el $13 \%$ de la muestra total al no concluir el cuestionario).

Para el proceso de edición de los datos se trabajó con 112 encuestas, sin presentarse casos perdidos, con lo que se procedió a vaciar la información en el software SPSS donde las respuestas cerradas ya contaban con una recodificación (Tabla 9).

\begin{tabular}{|l|l|}
\hline \multicolumn{2}{|c|}{ Análisis de los resultados } \\
\hline Análisis & Técnica \\
\hline $\begin{array}{l}\text { Perfil del Sector de Alta } \\
\text { Tecnología de México }\end{array}$ & Estadística descriptiva \\
\hline
\end{tabular}

Tabla 9 Técnicas estadísticas para análisis de datos del estudio

\section{Resultados}

Con el proceso anterior, se efectuó el análisis mediante estadística descriptiva para resumir o describir las características importantes de las empresas de alta tecnología en México, utilizándose las medidas de tendencia central, ya que dan cuenta del tipo de distribución que tienen los valores de la variable respecto de un valor típico o puntuación central, a partir del cual se agrupan.

Es decir, son un valor que está en el centro o punto medio de un conjunto de datos (Triola, 2000), estos se calculan para variables medidas a nivel nominal, ordinal o intervalo. Las medidas de dispersión o variación se utilizaron para analizar la distribución de los valores de una serie datos, si estos se encuentran más o menos concentrados o dispersos a la media. Cuanto mayor sea el valor es más la variabilidad y cuanto menor más homogeneidad. Las formas de distribución (Asimetría y Curtis), describen la forma de la distribución de una variable, sus características de simetría y homogeneidad sin la necesidad de ser graficadas. 


\section{Análisis de resultados}

A. Datos generales. De las empresas que participaron en el estudio de acuerdo con el giro el $50 \%$ son nacionales, del estado de Jalisco, del sector de manufactura, de más de 100 empleados denominada como grande (Gráficos 1-4), es importante señalas los datos en general presentan una distribución simétrica con un sesgo positivo, donde la media y la mediana están a la derecha de la moda (Triola, 2000).

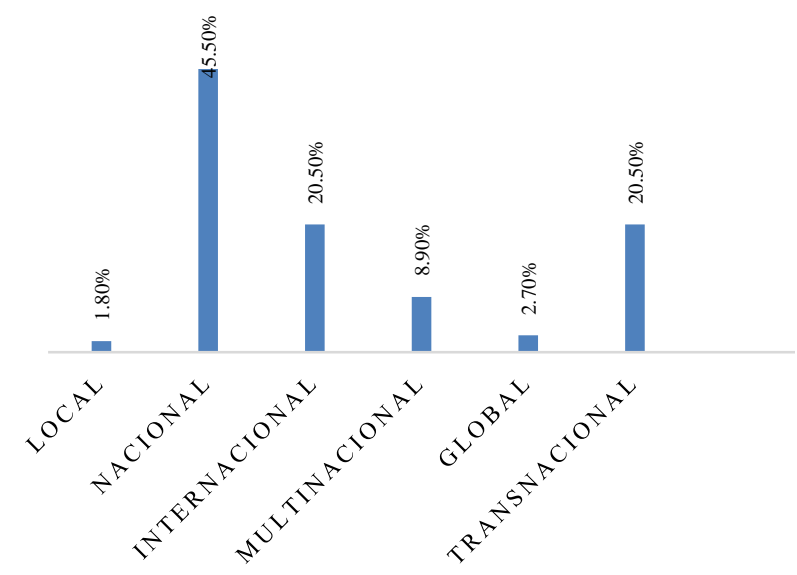

Gráfico 1 Giro de la empresa. Media=3.27. Desviación estándar $=1,588 . \mathrm{N}=112$



Gráfico 2 Entidades federativas. Media=3.78 Desviación estándar $=1,456 \mathrm{~N}=112$

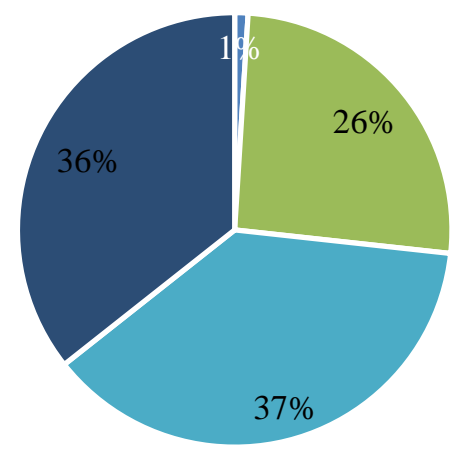

- Aeroespacial $\|$ Automotriz $~=$ Manufactura $-\mathrm{TI}$

Gráfico 3 Sector Industrial. Media= 3.08 Desviación estándar $=, 807 . \mathrm{N}=112$



Gráfico 4 Tamaño de la empresa. Media $=2.28$. Desviación estándar $=, 75 . \mathrm{N}=112$

En cuanto a las empresas que están dentro de un Clúster de las 112 el $53.60 \%$ pertenece al sector productivo correspondiente (Gráfico 5).

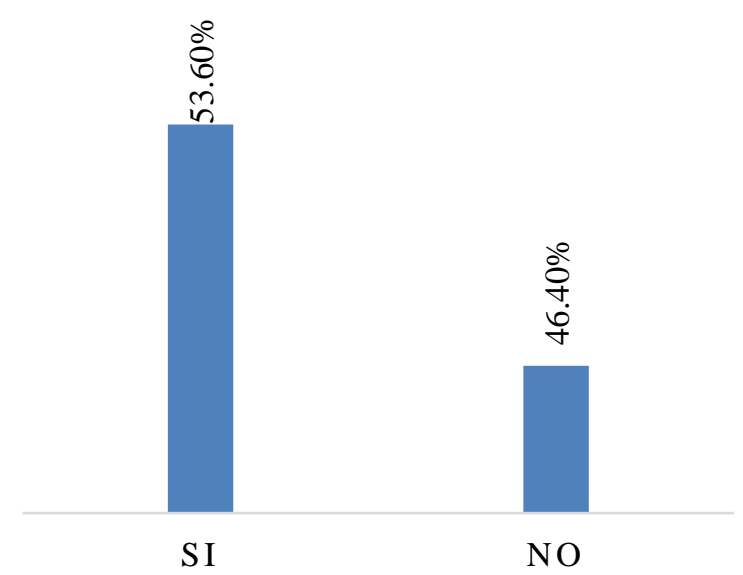

Gráfico 5 Las empresas forman parte de un Clúster. Media $=2.28$. Desviación estándar $=, 75 . \mathrm{N}=112$

El $60.7 \%$ de las empresas del sector de alta tecnología de México cuentan con área de Investigación, Desarrollo e Innovación (I+D+i), el $25.9 \%$ se ubica de manera interna en la organización y el $23.2 \%$ cuenta con área interna y externa, y sólo el $11.6 \%$ su departamento $\mathrm{I}+\mathrm{D}+\mathrm{i}$ está fuera de la organización (Ver gráfico 6).

VILLALOBOS-ALONZO, María de los Ángeles \& ROMO-GONZÁLEZ, Ana Eugenia. Perfil del sector de alta tecnología en México: Una aproximación a la realidad. Revista de Operaciones Tecnológicas. 2020 


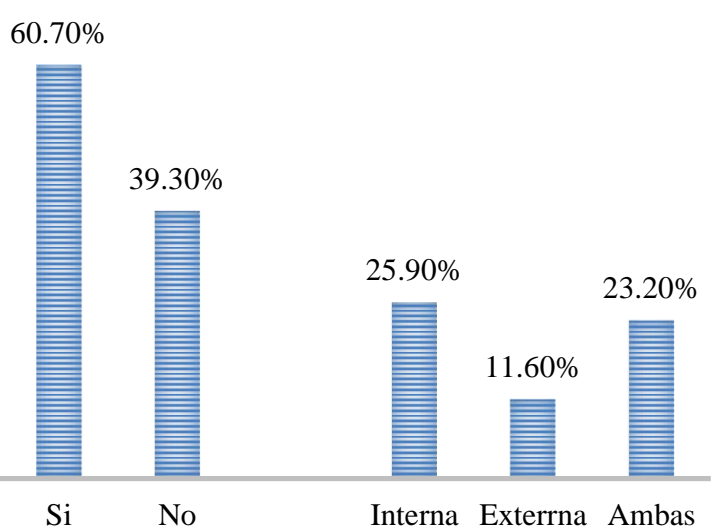

Gráfico 6 Cuenta con área I+D+i la organización y su ubicación. Media=3.27. Desviación estándar $=1,588$. $\mathrm{N}=112$

Hay que señalar que el $18.8 \%$ de las empresas de alta tecnología cuentan con registro RENIECYT (Gráfico 7).

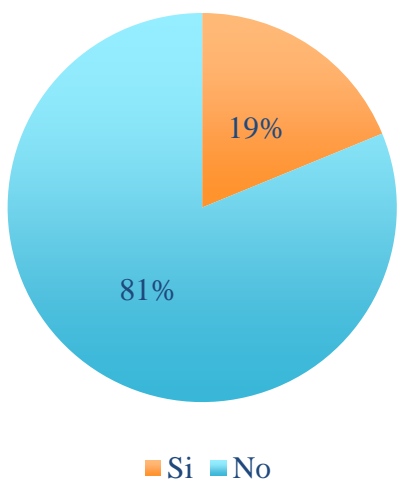

Gráfico 7 Cuenta con RENIECYT. Media= ,19. Desviación estándar $=, 392$. N=112

\section{B. Procesos de Investigación y Desarrollo} Tecnológico (IDT). En este apartado se realiza una descripción del capital humano que participa en actividades de $\mathrm{I}+\mathrm{D}+\mathrm{i}$ y su producción. Se identificaron 231 empleados en 68 empresas que tienen establecido un área enfocada a estas funciones, la distribución se presenta en el gráfico 8.



Gráfico $8 \mathrm{El}$ grado de formación profesional de las personas que trabajan en la empresa en actividades de investigación y desarrollo tecnológico innovación

ECORFAN ${ }^{\circledR}$ Todos los derechos reservados
Con nivel doctorado se localizaron cuatro colaboradores, los cuales se encuentran en empresas del sector Automotriz en Chihuahua (1), Jalisco (1) y Nuevo León (2), las empresas son de giro transnacional y Global, con más de 200 empleados (grande), cuentan con área de $\mathrm{I}+\mathrm{D}+\mathrm{i}$, interna y externa, pertenece a un Clúster, y están registrados en el RENIECYT.



Gráfico 9 Relación de Patentes, Modelos de utilidad y Propiedad intelectual en el sector de Alta Tecnología de México. P: Media= ,13 Desviación estándar= 383. MU: Media $=, 34$ Desviación estándar $=$,562. PI: Media $=, 19$ Desviación estándar=,414.

C. Inversión. La inversión en $\mathrm{I}+\mathrm{D}+\mathrm{i}$ de las empresas de alta tecnología de México durante los años 2016 y 2017 fluctúa entre 1\% al 2\% de las ventas anuales como se muestra en el gráfico 10.

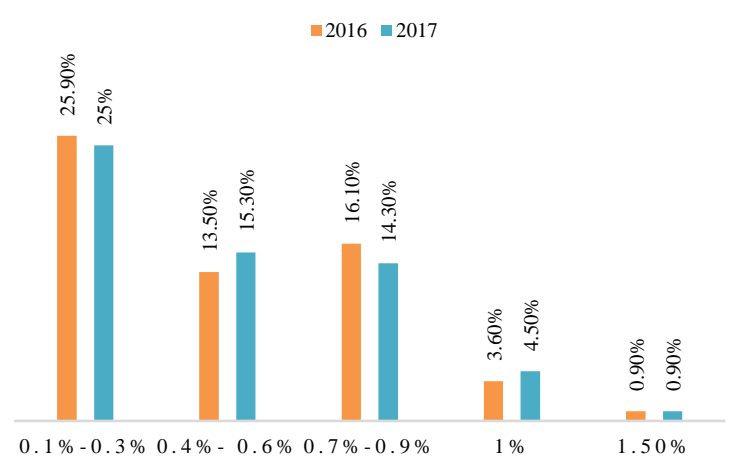

Gráfico 10 Gasto en I+D+i 2016 al 2017 en la industria de AT de México

VILLALOBOS-ALONZO, María de los Ángeles \& ROMO-GONZÁLEZ, Ana Eugenia. Perfil del sector de alta tecnología en México: Una aproximación a la realidad. Revista de Operaciones Tecnológicas. 2020 
El gasto en actividades de investigación y desarrollo tecnológico entre el 2012 y 2014 (Tabla 5-103) en las empresas de alta tecnología de México se encontró que Baja California en el sector TI gasta hasta el $.06 \%$, en Chihuahua el sector Manufacturero con .08$.09 \%$, en el Estado de México el sector Manufactura con .03-.08\%, en Jalisco se destacan dos industrias; Manufactura y TI con un gasto entre el $1 \%$ y $1.5 \%$. En Nuevo León se sitúa en la industria Automotriz y Manufactura con un gasto hasta el $.08 \%$. Puebla con el área Automotriz al igual que Querétaro con un gasto al $.04 \%$.

Las entidades que reportan mayor gasto en actividades de investigación y desarrollo tecnológica en los sectores de alta tecnología que las conforman son el Estado de México .02 al $.08 \%$, Jalisco del 01 al $1.5 \%$ y Nuevo León del 01 al .08\%, manteniendo muy baja variación $.01 \%$ porcentual en el periodo 20162017 en los diversos sectores.

Sobre las fuentes de los fondos dedicados a IDE en las empresas del sector AT se encontró como se muestra en el Gráfico 11, que el $61 \%$ de las empresas utilizan fondos propios, el $20 \%$ utilizan fondos privados, $5 \%$ los obtiene del sector gobierno, el $2 \%$ de la vinculación a fondos públicos generales universitarios, el 10\% de instituciones privadas no lucrativas y el 7\% del Exterior (Organismos internacionales).

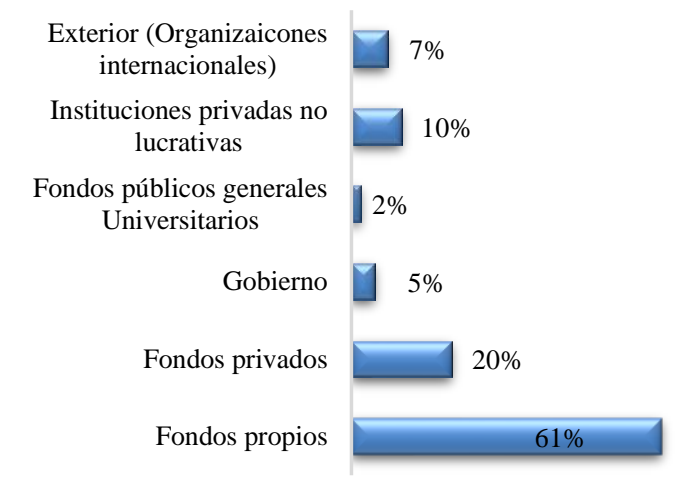

Gráfico 11 Fuentes de fondos de inversión en IDT

El sector Automotriz obtiene fondos para la inversión en IDE de las seis fuentes propuestas manteniendo una mayor participación entre los sectores de AT, le sigue Manufactura con una participación en cinco de las fuentes y TI sus fuentes se encuentran entre los fondos de propios, privados y del sector gobierno.

ISSN: 2523-6806

ECORFAN $^{\circledR}$ Todos los derechos reservados
De los fondos públicos generales universitarios se encuentran los sectores Automotriz (Jalisco) y Automotriz (Estado de México).

Fondos del sector gobierno utilizado como fuente de inversión en IDE se encuentra la industria Automotriz y Manufactura de Jalisco, y en TI en Baja California Norte. Fuentes en el exterior de organismos internacionales aparece una empresa de Automotriz en Jalisco y de Manufactura 2 en Nuevo León y Querétaro.

Como se muestra en el Gráfico 12-13 la inversión sustancial por parte de las 112 empresas de alta tecnología que participaron en el estudio, 64 se enfoca en la formación del capital humano como el recurso intangible más valioso para la organización, es la apuesta más fuerte de este sector tecnológico para el desarrollo de actividades en $\mathrm{I}+\mathrm{D}+\mathrm{i}$, de las cuales Manufactura representa el $46 \%$, Automotriz el $18 \%$ y TI el $24 \%$ del total de empresas.



Gráfico 12 Inversión en I+D+i de las empresas de AT de México, parte 1

La segunda opción para inversión en I+D+i es la relacionada con la Actualización de maquinaria, con una acumulación de 50 empresas que seleccionaron esta opción, de la cual destaca Manufactura con el 58\%, Automotriz 19\%, Aeroespacial y TI con $212 \%$.

VILLALOBOS-ALONZO, María de los Ángeles \& ROMO-GONZÁLEZ, Ana Eugenia. Perfil del sector de alta tecnología en México: Una aproximación a la realidad. Revista de Operaciones Tecnológicas. 2020 


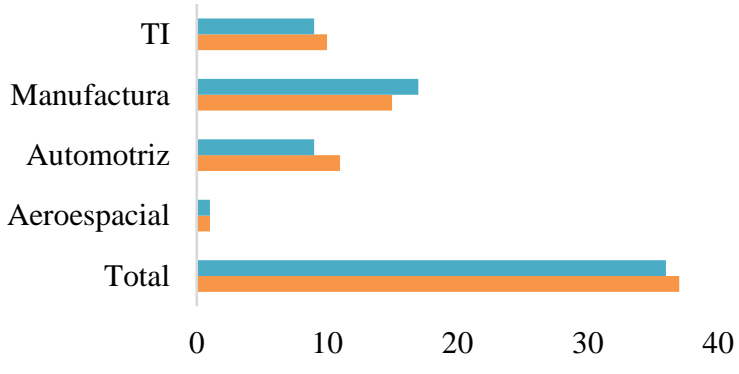

- Vigilancia tecnológica $\square$ Procesos organizacionales

Gráfico 13 Inversión en I+D+i de las empresas de AT de México, parte 2

La inversión en infraestructura tecnológica, procesos organizaciones y vigilancia mantienen una participación de empresas muy semejante, despuntando en el sector manufacturero.

C. Alianzas. Se indago sobre los convenios de cooperación con diferentes sectores que mantienen las empresas de alta tecnología.

De acuerdo con los resultados obtenidos, 80 de las empresas mantienen alianzas de cooperación, las cuales representan el $71.4 \%$ del total de las empresas que participan en el estudio (Gráfico 14). El 39\% pertenecen a Manufactura, el 27.5\% Automotriz y $32.5 \%$ a TI.

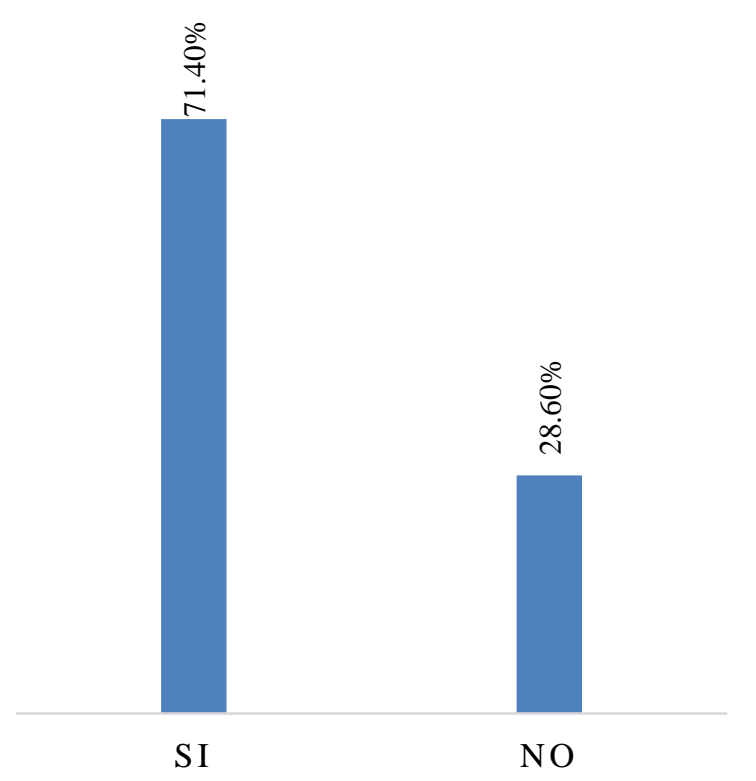

Gráfico 14 Alianzas de cooperación. Media= ,71. Desviación estándar $=, 454 . \mathrm{N}=112$
Las alianzas de las empresas de AT de México, con la categoría "sector productivo", el 49.1\% mantiene relación con instituciones de cooperación IDE (Gráfico 15) y con compañías afiliadas o asociadas como CANIETI, AMITI, AMIA (Asociación Mexicana de la Industria Automotriz), CANACINTRA, INA (Industria Nacional de Autopartes), FEMIA (Federación Mexicana de la Industria Aeroespacial), por mencionar algunas. Con el Gobierno, la alianza de mayor participación es la estatal con el $41.1 \%$ y con otras instituciones aparecen las privadas no lucrativas con el $55.4 \%$

\section{Sector productivo}

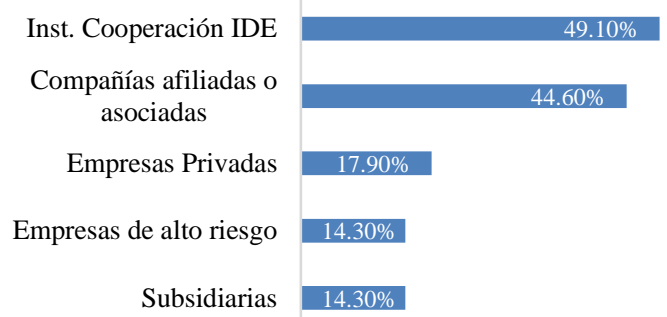

Gráfico 15 Alianzas y convenios de colaboración

De las alianzas por sector industrial y entidad federativa se encontró que en la categoría de Subsidiarias; tienen mayor participación las empresas del sector de Manufactura en las siete entidades federativas. Empresa de alto riesgo: el sector con mayor alianza es TI en el que participan cuatro entidades federativas y el segundo sector Automotriz. Con empresas privadas la mayor concentración de alianzas en la industria manufactura con la participación de 6 entidades federativas y el sector automotriz.

En relación con los convenios de colaboración con Instituciones de Educación Superior, se identificó que sólo el 30\% de las 112 empresas mantiene este tipo de alianza.

\section{Agradecimiento}

A las asociaciones y empresas de México que participaron en la encuesta aplicada para la realización de diagnóstico, por su valiosa contribución a este proyecto de investigación. 


\section{Conclusiones}

En cuanto al análisis descriptivo para el diseño del perfil del sector de alta tecnología en México, es importante señalar que el $60.7 \%$ de las empresas que participaron en el estudio cuenta con área de $\mathrm{I}+\mathrm{D}+\mathrm{i}$, del cual el $73.5 \%$ son empresas de giro internacional a transnacional que cuentan con áreas internas y externas de investigación y desarrollo.

En el caso de las empresas nacionales se identificó que aparecen dentro de la clasificación de sector de Alta Tecnología en México se encuentran en esta clasificación por el giro o actividad de la empresa, y no por obtener resultados como parte de un intenso proceso de Investigación y Desarrollo Tecnológico (IDT).

Las empresas nacionales tuvieron una mayor participación en el estudio con el $45.5 \%$ de las cuales sólo 17 empresas $(33.3 \%)$ cuentan con área de I+D+i, lo que demuestra que las empresas nacionales no tienen una rápida renovación de conocimientos, ni un continuo esfuerzo enfocado en investigación y desarrollo tecnológico, convirtiéndose en un área de oportunidad mediante la colaboración.

Para el financiamiento de actividades I+D+i es necesario señalar que sólo el $4.5 \%$ los obtiene mediante el sector gobierno, área de oportunidad para las estructuras y mecanismos de las políticas públicas para el impulso de actividades de investigación e innovación, mediante la colaboración.

La inversión para el desarrollo de actividades de I+D+i en las empresas del sector de alta tecnología de México, está enfocada a la Formación de Capital Humano, el recurso intangible más valioso para la organización ya que el conocimiento nuevo empieza siempre en la persona" (Nonaka, y Takeuchi, 2000) y a la actualización de maquinaria e infraestructura tecnológica, ya que las organizaciones que incorporan la tecnología o el desarrollo de los activos están en mejores condiciones que sus competidores para innovar (Fernández-Jardón, 2012).
En relación con alianzas, sólo el 30.4\% de las empresas colaboran con Instituciones de Educación Superior (IES) ya que consideran que la respuesta de la academia a problemas de la industria es muy lenta. Esta es un área de oportunidad mediante la colaboración en I+D con las universidades e institutos de investigación (Azagra-Caro, Archontakis, Gutiérrez-Gracia y Fernández-de-Lucio, 2006) para identificar oportunidades de innovación y transferencia de conocimiento.

La razón radica en que los investigadores se encuentran enfocados en el área académica y se ha vuelto primordial contribuir y aportar conocimiento en las empresas tecnológicas, una adecuada vinculación con la industria, sociedad, la academia y gobierno contribuyen a posicionar a México en el marco internacional de la economía del conocimiento.

\section{Referencias}

Alonzo, M. D. L. Á. V., \& González, A. E. R. (2015). Diseño y validación de cuestionario para la exploración de capacidades de innovación para empresas de alta tecnología de México. Revista QUID, (25)

Azagra-Caro, J. M., Archontakis, F., GutiérrezGracia, A., y Fernández-de-Lucio, I. (2006). Faculty support for the objectives of universityindustry relations versus degree of $R \& D$ cooperation: The importance of regional absorptive capacity. Research Policy, 35(1), 3755.

Barceló, M. (2001). Hacia una economía del conocimiento. Madrid: Esic.

Báscolo, P. J., Castagna, A. I., \& Woelflin, M. L. (2012). Intensidad tecnológica en la estructura productiva de Rosario. ¿Hacia una economía más intensiva en conocimiento? PAMPA, 1(8), 63-88.

Burgelman, R. A., Chistensen, C. M. y Wheelwringht, S. C. (2009). Strategic management of technology and innovation. Boston: McGraw-Hill. 
Caravaca, I., González, G., García, A., Fernández, V. y Mendoza, A. (2014). Conocimiento, innovación y estrategias públicas de desarrollo: análisis comparado de tres ciudades medias de Andalucía (España). EURE (Santiago) [online]. Vol.40, n.119, pp. 49-74. ISSN 0250-7161.

Corral, P. y Ramos, C. (2012). "La industria en el desarrollo económico de México". Observatorio de la Economía Latinoamericana, No $170,2012$.

Dankhe, G. L. (1976). Investigación y comunicación. In: DanHhe GL, organizador. La comunicación humana ciencia social (DC): McGraw Hill, p. 385-454.

Diario Oficial de la Federación (2013). Programa de Desarrollo Innovador 20132018. Secretaria de Gobernación México. Disponible en:

http://www.dof.gob.mx/nota_detalle.php?codig $\mathrm{o}=5326479 \&$ fecha $=16 / 12 / 2013$

Dillman, D. A., Reips, U. D. y Matzat, U. (2010). Advice in surveyingthe general public over the internet. International Journal of Internet Science, 5(1), 1-4.

Fernández-Jardón, C. M. (2012). Determinantes de la capacidad de innovación en PYMES regionales. Revista de Administração da UFSM, 5, 749-765.

Fleiss, J. L. [1971]. Measuring nominal scale agreement among many raters. Psychological Bulletin 76, 378-382

González, A. (2012). Hay 38 clústeres mexicanos. Noticias de la Cámara Nacional de la Industria Electrónica, de Telecomunicaciones y Tecnologías de la Información (CANIETI). 09/04/2012. Recuperado de: canieti.org/Comunicacion/noticias/vista/12-

González, M. A. P. (1998). Proyectos de vinculación: una metodología. Ingenierías, 1(2), 1.

Gutiérrez, S. N. G. (2004). La vinculación en el ámbito científico-tecnológico de México. Revista Latinoamericana de Estudios Educativos, XXXIV, 47-94.
Hatzichronoglou, T. (1997), "Revision of the High-Technology Sector and Product Classification", OECD Science, Technology and Industry Working Papers, 1997/02, OECD Publishing.

http://dx.doi.org/10.1787/134337307632 Pág. 2 68

Hausmann, R., Hidalgo, C. A., Bustos, S., Coscia, M., Chung, S., Jimenez, J., y Y1ldırım,

Hernández, R., Fernández, C., Baptista, P., (2010). Metodología de la investigación. Quinta edición. México: Editorial McGraw-Hill.

Instituto Nacional de Estadística [INE]. (2002). Sector de alta tecnología. Instituto Nacional de Estadística, España. Recuperado de: http://www.ine.es/daco/daco43/notaiat.pdf

(2013). CNAE 2009. Clasificación Nacional de Actividades Económicas, España. Recuperado http://www.ine.es/prensa/np895.pdf www.ine.es/daco/daco42/daco4217/lstsectcnae. Xls

(2015). Producto interno bruto a precios corrientes. Consultado en: http://www.inegi.org.mx/inegi/contenidos/notas informativas/pib_precr/NI-PIBCR.pdf

Landis, J. R. y Koch, G. G. (1977). The measurement of observer agreement for categorical data. biometrics, 159-174.

McKenna, R. (1985). Market Positioning in High Technology. California Management Review, vol. 37, núm. 3. 82-108.

Méndez, R. (2002). Innovación y desarrollo territorial: algunos debates teóricos recientes. Revista Latinoamericana de Estudios Urbanos Regionales (EURE), 28(84), pp. 63-83.

Mohr, J. J., Sengupta, S., y Slater, S. F. (2009). Marketing of high-technology products and innovations. Pearson Prentice Hall

Molero-Zayas, J. M., e Hidalgo, A. (2003). Los sectores de alta tecnología. Estructura Económica de Madrid (pp. 441-468).

Moriarty, R., y Kosnik, T. (1989). High Tech Marketing: Concepts, Continuity and Change. Sloan Management Review, vol. 30, 7-17. 
Nonaka, I. y Takeuchi, H. (2000). La empresa creadora de conocimiento. Harvard Business Review. Gestión del conocimiento. Germán Orbegozo (Trad.). Bilbao. Ediciones Deusto, 200, 23-49.

Oakey, R. P., Rothwell R. y Cooper, S. (1988). The management of innovation in hightechnology small firms: innovation and regional development in Britain and the United States. London: Pinter.

Organización para la Cooperación y el Desarrollo Económico [OCDE]. (2012). México mejores políticas para un desarrollo incluyente. Recuperado de: http://www.oecd.org/mexico/Mexico\%202012 \%20FINALES\%20SEP\%20eBook.pdf

Organización Mundial de las Naciones Unidas [ONU]. (2009). International Standard Industrial Classification of All Economic. Series M No. 4/Rev.4. Recuperado de http://unstats.un.org/unsd/publication/seriesM/s eriesm_4rev4s.pdf

Pérez, J. E. A. (2012). Asociaciones entre madurez de gestión del conocimiento y desempeño innovador: organización y personas, e interpretación. Revista Lasallista de Investigación, 9(1), 86-95.

Plan Nacional de Desarrollo 2013-2018 (2013). Gobierno de la República de México. Recuperado de: http://pnd.gob.mx/.

ProMéxico. (2013). Investment Map. Información estatal del sector aeroespacial. Recuperadode:

http://mim.promexico.gob.mx/JS/MIM/Informa cionEstatal/sectores/AERO/listaesp.pdf

Real Academia Española. (2014). Tecnología. En Diccionario de la lengua española (23. Ed.). Recuperado http://lema.rae.es/drae/?val=Tecnologia

Rodríguez-Pose, A. (2012). Los parques científicos y tecnológicos en América Latina: Un análisis de la situación actual. Banco Interamericano de desarrollo.

Ruiz, D. C. (2008). México: Geografía económica de la innovación. Revista Comercio Exterior, Vol. 58, no 11 , noviembre, pp. 756768. México.
Ruiz, R. F. (2004). La innovación empresarial a través de I+D en Andalucía. Cuadernos de Geografía de la Universidad de Valencia, $n^{\circ} 75$, pp. 053-074.

Secretaría de Educación Pública. (2013). Educación Superior Pública. Subsecretaría de Educación Superior. Recuperado de: http://www.ses.sep.gob.mx/wb/ses/educacion_s uperior_publica

Sistema de Clasificación Industrial de América del Norte, México SCIAN (2013). México: INEGI, 2013. Recuperado de: http://www.inegi.org.mx/est/contenidos/proyect os/SCIAN/presentacion.aspx

Storey, D. J. y Tether, B. S. (1998). New technology-based firms in the European union: an introduction, Research Policy, 26.

Tello, F. P. H., Moscoso, S. C., Abad, E. V., Egido, B. D., Sanduvete-Chaves, S., y García, M. I. B. (2015). Evaluación de programas de formación continua en contextos no estandarizados: complementariedad entre Análisis Factorial y Multinivel para la obtención de evidencias de validez de constructo. Anales de psicología, 31(2), 725732.

Triola, M. F. (2000). Estadística elemental. Pretice Hall.

Tristán-López, A. (2008). Modificación al modelo de Lawshe para el dictamen cuantitativo de la validez de contenido de un instrumento objetivo. Avances en medición, 6(1), 37-48.

Villalobos, M., \& González, A. E. R. (2015). Diseño y validación de cuestionario para la exploración de capacidades de innovación para empresas de alta tecnología de México. QUID: Investigación, Ciencia y Tecnología, (25), 5.

Zikmund, W. y Babin, B. (2009). Investigación de Mercados (Novena edición ed.). México DF, México: Cengage Learning 